\title{
Mulheres testosteronadas: adictas, malditas, transgressoras, bombásticas?
}

Testo Yonqui.

PRECIADO, Beatriz.

Madrid: Espasa, 2008. 324 p.

Beatriz Preciado é filósofa, estudou teoria de gênero na New School for Social Research, em Nova York, onde foi aluna de Jacques Derrida e Agnès Heller. É autora do livro Manifesto contrasexual, traduzido para cinco idiomas, e entre seus ensaios destacamos Sex Design (Centre Pompidou, 2007), Multitudes Queer (Multitudes, 2004) e Savoirs-Vampires@War (Multitudes, 2005). Atualmente, ensina teoria contemporânea de gênero em diferentes universidades, entre as quais destacamos Paris VIII, l'École des Beaux Arts de Bourges, e Programa de Estudios Independientes del Museu d'Art Contemporani, de Barcelona. A autora se fundamenta nas teorias feministas contemporâneas, que problematizam a performatividade dos gêneros e servem como marco conceitual para discutir corpo, sexualidade e gênero.

O livro Testo Yonqui é dividido em 13 capítulos, dentre os quais destacamos as seguintes discussões: era farmacopornográfica; história da tecnossexualidade; farmacopoder; pornopoder; micropolítica de gênero na era farmacopornográfica; e vida eterna. Preciado qualifica sua obra como livro de autoficção, pois se trata de um protocolo de intoxicação voluntária à base de testosterona sintética, de um ensaio corporal, do corpo experimental em mutação no período que dura a escrita do livro. Ela descreve o uso da testosterona sintética em forma de gel, que é absorvida na pele; basta uma dose de 50 miligramas de Testogel diárias para experienciar o que ela nomeia como mutação de uma época.

A proposta do livro é de uma análise sexopolítica da economia mundial, em que a testosterona sintética pode representar tanto uma construção tecnológica de um novo tecnopoder difuso como a possibilidade de mudança identitária para as mulheres através da experiência transexual. Sua toxidade difere dos psicotrópicos justamente pela capacidade de mutação de humores que transitam nas relações generificadas, pela associação biológica que se fez com a masculinidade hegemônica; portanto, sua experiência não é tão mental quanto sexual. Ela faz os/as leitores/ as embarcarem em uma cronologia das transformações da produção industrial do último 
século, do ponto de vista da conversão progressiva em uma gestão política e técnica do corpo, do sexo e da sexualidade. Para tal, ela se pergunta como o sexo converteu-se no centro da atividade políica e econômica atual e qual sua relação com os produtos farmacoquímicos.

Um longo percurso nos faz visualizar possíveis pistas. Durante o período da Guerra Fria os Estados Unidos investiram milhões de dólares em pesquisas científicas sobre o sexo e a sexualidade como nenhum outro país ao longo da história. A mutação do capitalismo vem sendo a transformação do sexo em objeto de gestão política da vida, tal como já apontava Michel Foucault ao descrever a biopolítica e as novas formas de controle social. No final da Primeira Guerra Mundial vê-se o momento de visibilidade das mulheres nos espaços urbanos, assim como a emergência de formas visíveis e politizadas da homossexualidade em espaços inesperados, tais como no exército norte-americano. O macartismo americano dos anos 1950 soma perseguição aos comunistas com a luta anti-homossexualidade como forma de patriotismo e ao mesmo tempo ressalta valores como família, masculinidade laboriosa e feminilidade doméstica. No Ocidente inúmeros centros de pesquisa sobre sexualidade iniciam suas atividades. George Henry e Robert Dickinson realizam a primeira demografia dos "desvios sexuais", estudo epidemiológico chamado Sex Variant, e mais tarde o Relatório Kinsey sobre a sexualidade do povo norte-americano. O sexo se transforma rapidamente em objeto de especulação e controle social.

Preciado mostra-nos um capitalismo quente, psicotrópico e punk emergindo juntamente com essa avalanche de preocupações em torno do sexo. Índices da aparição de um regime pósindustrial, global e midiático que toma como referência os processos governamentais biomoleculares (fármaco) e semiótico-técnico (pornográfico) da subjetividade sexual, nomeado pela autora de regime farmacopornográfico. Em 1946, com a criação da primeira pílula anticoncepcional à base de estrógeno sintético, a indústria farmacoquímica entra na era hormonal e a pílula logo se converte na molécula farmacêutica mais usada na história da humanidade. Em 1947 os laboratórios Eli Lilly (Indiana, EUA) manipularam e comercializam a metadona (um opiáceo simples), usada como analgésico que nos anos 1970 substituiu a adição de heroína. No mesmo ano:

El pseudopsiquiatra norteamericano John Money inventa el término "género" diferenciándolo del tradicional "sexo" para nombrar la pertencia de um individuo a um grupo culturalmente reconocido como "masculino" o "femenino" y afirma que es posible "modificar el género de cualquier bebé hasta los dieciocho meses" (p. 28).

Sexo e gênero não seriam mais os mesmos. Com as fronteiras de gênero rompidas, a tecnofabricação dos corpos sexuados alavanca uma das indústrias de maior crescimento nas últimas décadas: a indústria farmacêutica. A manipulação dos hormônios e a criação dos sintéticos consolidam a tecnofabricação dos corpos sexuados.

Com a criação do plástico para fabricação de objetos do cotidiano, definem-se as condições materiais de transformação ecológica em grande escala, tais como destruição dos recursos naturais e energéticos do planeta, consumo rápido e alta contaminação. Rápida mutação que, também, representa rápida destruição planetária em massa. A vida é colocada em questão, pois pode ser destruída, reconstruída e criada a qualquer momento. Náo se trata mais da questão de reprimir o sexo, mas colocá-lo em evidência, transformá-lo, recriá-lo, manipulálo. Em 1953 o soldado americano George W. Joorgensen se transforma em Christine, a primeira transexual midiatizada. No mesmo ano é criada a Playboy, seguindo-se uma rápida e crescente produção desse tipo de publicação. Carne fresca exposta nas prateleiras das livrarias e das papelarias. Representação de uma nova relação com o corpo, entendido como produto manipulável, comercializável e rentável.

Em 1958, na Rússia, leva-se a cabo a primeira faloplastia, construção de um pênis a partir de enxerto de pele dos músculos do braço, como parte de um processo de mudança de sexo de mulher para homem. Em 1960 o laboratório Eli Lilly comercializou o secobarbital, um barbitúrico com propriedades analgésicas que se converteu em uma das drogas da cultura underground dos anos 1960. Em 1966 elaboramse os primeiros antidepressivos que atuam diretamente na síntese da serotonina e que levaram até a criação da fluoxetina em 1987, comercializada com vários nomes, dos quais o mais divulgado foi o Prozac. Em 1971 o Reino Unido estabeleceu a lei de abuso de drogas, que regulamenta $o$ consumo e $\circ$ tráfico de substâncias psicotrópicas. Em 1977 os Estados Unidos induziram a primeira injeção letal, à base de um composto barbitúrico, para aplicar a pena capital semelhante ao chamado "Programa de Ação T4" de higiene racial que a Alemanha nazista usou para assassinar milhares 
de pessoas com deficiência física e psíquica. Em 1983 a transexualidade, divulgada como disforia de gênero, se inclui na lista das Doenças de Saúde Mental (DSM) como enfermidade mental. Nos anos 1980 descobrem-se e comercializam-se novos hormônios como DHEA e GH. E no fim do século XX cerca de quatro milhões de crian-ças são tratadas com ritalina para o chamado "déficit de atenção". Vemos nascer assim uma sociedade masturbatória embalada com dro-gas sintéticas para todos os gostos e persona-lidades, usadas seja para tratar a agitação, seja para induzi-la.

Há uma produção de estados mentais e psicossomáticos de excitação, relaxamento, descarga, onipotência e controle total, cujos produtos são a serotonina, a testosterona, os antiácidos, a cortisona, os antibióticos, o estradiol, o álcool, o tabaco, a morfina, a cocaína e o citrato de sidenofil (Viagra). Não há nada para ser descoberto na natureza, não há mais segredos, a verdade do sexo não é o desvelamento, mas o sex design. Diz a autora: "El éxito de la tecnociência contemporânea es transformar nuestra depresión em Prozac, nuestra masculinidad em testosterona, nuestra eréccion em Viagra, nuestra fertilidad/esterilidad em píldora, nuestra sida em triterapia" (p. 33). Ela entende o atual mercado do sexo como amador, não mais de domínio multinacional como já foi a Playboy e as muitas outras revistas do gênero, o sexo é virtual e instantâneo. A internet produz crônicas audiovisuais das vidas sexuais de uma infinidade de pessoas no mundo; para isso basta ter um corpo, uma web câmera, uma conexão de internet e um cartão de crédito. Com isso é possível criar sua própria página pornográfica e ascender ao mercado globalizado da indústria do sexo. Essa realidade virtual provocou uma ruptura com o monopólio que até então detinham as grandes multinacionais pornográficas.

Para a autora, a indústria do sexo é o mercado que mais cresce e o mais rentável da internet, somente comparável à especulação financeira. Dentro da lógica masturbatória do consumo pornográfico existe uma ideia de venda direta do produto em tempo real produzindo satisfação imediata ao consumidor. A assepsia do gozo virtual associada aos fármacos cria um novo pornopoder. Ela lança a hipótese de que a matéria-prima do processo produtivo atual é a excitação, a ereção, a ejaculação, o prazer e o sentimento de autocomplacência e controle onipresente. $O$ motor do capitalismo atual é o controle farmacopornográfico da subjetividade.
Preciado apresenta um corpo tecnovivo e multiconectado. Ela incorpora a tecnologia tematizada por Haraway e lança-a no centro da indústria farmacoquímica, preferindo o termo "tecnobiopoder" ao "biopoder" foucaultiano, pois não se trata somente do poder sobre a vida, mas poder e controle sobre todo tecnovivo conectado.

A descrição técnica da testosterona pressupõe que o usuário seja um homem que não produz naturalmente uma quantidade suficiente de andrógenos e, como consequência, que seja heterossexual, pois relaciona a parceira sexual como mulher. A noção de homem faz referência à definição cromossômica $\mathrm{XY}$, genital, que possui pênis e testículos ou definição legal, que menciona homem na Carteira de Identidade. Em todo caso é necessário deixar de identificar-se como mulher para obter legalmente uma dose de testosterona, embora ela seja comercializada no mercado negro e facilmente encontrada na internet. É essa relação hormônio"gênero que é virulentamente criticada como nova produtora dos corpos sexuados. $\mathrm{Na}$ história da sexualidade foucaultiana o que eram práticas sexuais se convertem em identidades, condições políticas a serem estudadas, catalogadas, perseguidas ou curadas. Cada corpo tem um indivíduo que é necessário corrigir. Por exemplo, a mulher barbada, na nova epistemo-sexualidade, se converte em objeto de investigação para se verificarem os níveis de testosterona numa fêmea ou então vira em espetáculo circense.

Segundo Preciado, a relação entre esporte e prostituição é uma das chaves para a compreensão do que ela nomeia como atual regime farmacopornográfico. Cita o exemplo da Copa de 2006, quando o Governo alemão incentivou a "fordização da indústria sexual" criando a Artemis, um prostíbulo multimídia de três mil metros quadrados situado a três quarteirões do Estádio Olímpico de Berlim. Nele foram instalados quatro andares com piscinas, saunas, salas de cinema e internet, quartos suficientes para mais de 40 mil trabalhadoras do sexo atendendo uma média de 600 clientes por dia no local e milhares on-line. Trabalhadoras do sexo migraram com autorização temporária de vários lugares do mundo. Na ocasião, na França, houve uma manifestação do Coalicion Internacional Contra el Tráfico de Mujeres (CATW), cujo slogan "Acheter de sexe n'est pas un Sport" (comprar sexo não é um esporte) leva a crer que realmente sexo é um esporte relacionado a uma rede de expressão do corpo sexualizado e ao universo das 
drogas e de hormônios sintéticos do tráfico internacional.

O futebol como cultura de massa pode aqui ser pensado em sua íntima relação com a prostituição e, assim, ser inserido na indústria farmacopornográfica, que controla redes de internet, clubes, boates, distribuição e difusão da pornografia, indústria farmacêutica, tráfico de drogas e de esteroides anabolizantes, e outros artefatos usados para suplementar tanto - corpo desportista como o corpo sexuado.

A testosterona sintética não muda o sexo, mas o descodifica, modifica em seus afetos e percepções. Uma mulher, quando inicia seus ciclos de testosterona, perde-se na difusa área divisória dos gêneros, pois nem é homem nem será 'a mulher', no sentido que Wittig' aborda, como uma semiótica dominante atrelada à subserviência e à dominação masculina. A testosterona é, portanto, dinamite para o regime heterossexista e está ali sua periculosidade.

Algumas inquietações podem emergir na leitura desta bombástica obra. São elas: o que aconteceria se as mulheres começassem a administrarem-se doses suficientes de testosterona para serem identificadas socialmente como homens? Que valor teria então a masculinidade? Que representações médicas são divulgadas quanto ao uso da testosterona sintética? A masculinidade e a feminilidade impressas no corpo são fisiológicas, políticas ou tecnológicas?

Sua proximidade com teóricas feministas contemporâneas como Butler, Haraway e Bourcier está em problematizar a transgressão das fronteiras do gênero, e seu distanciamento é notadamente a capacidade de escrever sobre temas aos quais os feminismos vinham dando pouca atenção. Os poderes da indústria farmacoquímica são em Preciado indissociáveis de sua crítica radical ao pornopoder e da indústria midiatizada do sexo.

\section{Notas}

'Monique WITTIG, 1992.

\section{Referência bibliográfica}

WITTIG, Monique. The Straight Mind: And Other Essays. Boston: Beacon Press, 1992.

Patrícia Lessa Universidade Estadual de Maringá 